\title{
Analisis Kebutuhan Limited Slip Differential (LSD) pada Mobil Formula Sapuangin Speed 6 di Ajang Student Formula Japan (SFJ)
}

\author{
Khalikul Haqqur Rahman dan I Nyoman Sutantra \\ Departemen Teknik Mesin, Institut Teknologi Sepuluh Nopember (ITS) \\ Corresponding Author: tantra@me.its.ac.id
}

\section{ARTIKEL INFO}

\section{Informasi Artikel}

Artikel masuk :

Artikel revisi :

Artikel diterima :

\section{Kata Kunci}

Clutch Plate LSD, Limitted Slip Differential (LSD), Ramp Angle LSD, Sapuangin Speed 6, Skid/Roll.

\begin{abstract}
ABSTRAK
Perkembangan teknologi pada mobil semakin banyak. Salah satunya Limited Slip Differential (LSD), yang diaplikasikan pada sistem powetrain dari mobil. Ketika mobil berbelok dan salah satu roda kehilangan gaya normalnya maka mobil akan mengalami guling, kemudian roda yang menempel dijalan akan kehilangan traksinya. Maka dari itu perlu adanya analisa kebutuhan LSD terhadap power, torsi dan kecepatan yang dapat disalurkan pada setiap variasi locking percentage. Dalam penelitian ini, analisa perhitungan dilakukan berdasarkan FBD mobil pada saat berbelok pada lintasan student formula. Menghitung kecepatan yang diijinkan, kemudian menghitung kecepatan yang harus ditempuh, selanjutnya analisa skid dan guling, dan yang terakhir menghitung Road-Load Horse Power (Rhp), Torsi roda saat berbelok yang dapat disalurkan oleh LSD pada salah satu roda. Perhitungan pada analisa ini diberikan variasi clutch plate $(0011 / 60 \%, 0101 / 100 \%)$ dan variasi ramp angle $(90 \% \%, 60 \% 29 \%$, $50 \% 42 \%, 45 \% 15 \%, 40 \% 60 \%, 30 \% 80 \%)$ yang dilakukan pada skidpad $(\mathrm{R}=8,55 \mathrm{~m})$, hairpin turns pada autocross dan endurance $(\mathrm{Rmin}=4,5 \mathrm{~m})$ serta pada constant turns pada autocross dan endurance ( $\mathrm{R}=11 \mathrm{~m}-27 \mathrm{~m})$. Dari analisa radius kritis (hairpin turns) yang dipengaruhi LSD didapatkan hasil penggunaan LSD akan optimum pada locking pecentage LSD terbesar, ketika mobil SAS 6 melaju dengan kecepatan 18,37 m/s, akan menyebabkan roda mobil terangkat maksimal pada hairpin turns radius 4,5 $m$ dengan sudut angkat $17,999^{\circ}$. Dan ketika tidak menggunakan LSD $(\mathrm{LP}=0 \%)$ maka tenaga mobil ( $\mathrm{Rhp})$ adalah 0 watt dan menghasilkan kecepatan untuk melaju $0 \mathrm{~m} / \mathrm{s}$, serta torsi pada roda bagian luar 3,884 Nm. Ketika menggunakan LSD dengan locking percentage (LP) $88 \%$, mobil akan memiliki tenaga (Rhp) sebesar 2477,352watt yang akan menyebabkan mobil memiliki kecepatan $17,480 \mathrm{~m} / \mathrm{s}$ dan torsi roda sebesar $17,999 \mathrm{Nm}$. Dan untuk pemilihan LSD harus memiliki initial torque sama dengan nilai torsi roda pada saat roda mulai terangkat.
\end{abstract}

\section{PENDAHULUAN}

Tahun 2018 ini ITS Team Sapuangin kembali berpartisipasi pada ajang tahunan Student Formula Japan (SFJ, yang tiap tahun diadakan di Shizuoka Stadium, Japan. SFJ merupakan event yang diadakan oleh Society of Automotive Engineering (SAE) dunia yang merupakan event untuk menunjukkan kemampuan merancang, membuat dan memasarkan mobil formula antar mahasiswa didunia yang dinaungi oleh FSAE dunia. SFJ terdiri dari beberapa event, yaitu Dynamic Event dan Static Event, Dynamic Event terdiri dari Acceleration, Skidpad, Autocross, Endurance dan Fuel Efficiency, pada Static Event terdiri dari Design Report, Cost Report dan Business Plan Pesentation.

Pada mobil Sapuangin Speed (SAS) 6 yang berlaga di Jepang ada beberapa kendala, seperti rem, mesin, dan plenum. Pada studi ini akan dibahas bagaimana kinerja Limited Slip Differential pada kemampuan akselerasi dan manuver mobil. Mobil yang menggunakan mesin 4 silinder berkapasitas $600 \mathrm{cc}$ ini menggunakan mekanisme pembatas slip roda pada gardan. Pada hasil SFJ yang sudah berlangsung pada 4-8 September 2018, mobil SAS 6 mendapatkan peringkat Over All 60 dari 93 tim, dimana pada acceleration peringkat 62 , skid pad peringkat 58, autocross peringkat 61 dan enduance peringkat 60. Jika dilihat dari peringkat dynamic event SAS 6 masih jauh dari peringkat 1. Pada event skid pad, Bimasakti Racing Team dari Universitas Gajah Mada (UGM) mencatatkan waktu terbaiknya 5,134 detik/putaran dan menempatkan posisinya pada peringkat 10 , Joanneum Racing Graz dari UAS Graz (Austria) mencatatkan waktu terbaiknya 4,860 detik/putaran dan menempatkan posisinya pada peringkat 1, sedangkan Sapuangin Speed 6 yang mencatatkan waktu 6,993 detik/putaran menempatkan posisinya pada peringkat 58. Dapat dilihat dari perbedaan waktunya memang tidak signifikan, namun waktu tiap milidetik nya sangat berharga, karena perbedaan waktu yang kecil pun dapat mempengaruhi skor dan peringkat. Dan 
Tabel 1. Spesifikasi mobil SAS 6

\begin{tabular}{|c|c|c|}
\hline 1 & Panjang & $2897 \mathrm{~mm}$ \\
\hline 2 & Lebar & $1412 \mathrm{~mm}$ \\
\hline 3 & Tinggi & $1211 \mathrm{~mm}$ \\
\hline 4 & Wheelbase & $1560 \mathrm{~mm}$ \\
\hline 5 & $\begin{array}{l}\text { Trackwidth Depan } \\
\text { Trackwidth Belakang }\end{array}$ & $\begin{array}{l}1260 \mathrm{~mm} \\
1200 \mathrm{~mm}\end{array}$ \\
\hline 6 & Berat kendaraan & $225 \mathrm{~kg}$ \\
\hline 7 & Area & $1,002 \mathrm{~m}^{2}$ \\
\hline 8 & $\mathrm{C}_{\mathrm{D}}$ & 0,605 \\
\hline 9 & $\mathrm{C}_{\mathrm{L}}$ & 0,00868 \\
\hline $\begin{array}{l}1 \\
0\end{array}$ & Berat pengemudi & $75 \mathrm{~kg}$ \\
\hline $\begin{array}{l}1 \\
1\end{array}$ & Peak Power (wheel) & $38 \mathrm{HP} / 8200 \mathrm{rpm}$ \\
\hline $\begin{array}{l}1 \\
2\end{array}$ & Peak Torque (engine) & $32,5 \mathrm{Nm} / 8300 \mathrm{rpm}$ \\
\hline $\begin{array}{l}1 \\
3\end{array}$ & $\begin{array}{l}\text { Cusco LSD Type MZ } \\
\text { (Initial Torque) }\end{array}$ & $127,49-147,1 \mathrm{Nm}$ \\
\hline $\begin{array}{l}1 \\
4\end{array}$ & $\begin{array}{l}\text { LSD Drexler FSAE } \\
\text { (Initial Torque) }\end{array}$ & $20-25 \mathrm{Nm}$ \\
\hline $\begin{array}{l}1 \\
5\end{array}$ & Diameter Roda & 10 inch \\
\hline \multirow{2}{*}{$\begin{array}{l}1 \\
6\end{array}$} & $\begin{array}{l}\text { Parameter Ban } \\
\text { Ban Depan (Hoosier LC0 } \\
\text { 6.0x18.0-10) }\end{array}$ & $\begin{array}{l}\mu(\mathrm{x}): 2,48 \\
\mu(\mathrm{y}): 2,37 \\
\text { frf: } 0,013\end{array}$ \\
\hline & $\begin{array}{l}\text { Ban Belakang (Hoosier } \\
\text { R25B 18.0x6.0-10) }\end{array}$ & $\begin{array}{l}\mu(\mathrm{x}): 2,32 \\
\mu(\mathrm{y}): 2,18 \\
\text { frr: } 0,010\end{array}$ \\
\hline 1 & Rasio gardan (ig) & (52/16) 3,25 \\
\hline $\begin{array}{l}1 \\
8\end{array}$ & Rasio transmisi (it) & $\begin{array}{l}\text { it } 1:(38 / 14) 2,714 \\
\text { it } 2:(33 / 15) 2,200 \\
\text { it } 3:(37 / 20) 1,850 \\
\text { it } 4:(32 / 20) 1,600 \\
\text { it } 5:(27 / 19) 1,421 \\
\text { it } 6:(26 / 2) 1,300\end{array}$ \\
\hline
\end{tabular}

dalam ajang ini optimalisasi setiap bagian sangat diperlukan untuk menghasilkan waktu yang maksimal.

Salah satu penyebab mobil sapuangin speed 6 tidak optimal adalah diakibatkan tenaga mesin yang besar tidak dapat tersalurkan dengan baik pada roda, sehingga mobil tidak memiliki gaya dorong/traksi maksimal untuk melawan gaya hambat, seperti gaya rolling, gaya hambat angin. Pemilihan rasio transmisi juga akan sangat berpengaruh pada daya yang dapat disalurkan.

Pada mobil Sapuangin Speed 6 menggunakan pembagi daya Limited Slip Differential (LSD). LSD adalah salah satu alat yang bisa menunjang untuk memaksimalkan traksi. LSD kurang lebih sama seperti Open Differential (gardan biasa), tetapi pada kondisi roda yang memiliki traksi rendah LSD mampu mentransfer torsi lebih dari open differential. Teori limited slip adalah factor locking dalam presentase, seberapa banyak torsi yang diberikan dapat diteruskan pada satu poros.

Dalam studi ini, dilakukan analisa tentang kinerja penggunaan LSD pada sistem transmisi mobil SAS 6. Langkah pertama harus mengetahui karakteristik mesin Kawasaki ZX6R 600cc standard meliputi kecepatan maksimum, torsi maksimum, daya maksimum, kemudian dilakukan analisa untuk memilih parameter yang tepat. Selain itu dilakukan juga analisa traksi saat belok yang berhubungan dengan pengaruh pemakaian Limitted Slip Differential (LSD) pada mobil SAS 6 terhadap radius belok lintasan agar dalam perancangan mobil baru untuk kompetisi selanjutnya lebih baik dalam akselerasi dan bermanuver. Hal ini dilakukan untuk mempersiapkan lebih dini dalam menghadapi event Student Formula Japan 2019 yang akan datang agar mobil
Sapuangin Speed dapat bersaing dengan baik dengan tim-tim papan atas didunia dan di Jepang pada khususnya.

\section{URAIAN PENELITIAN}

Pada penyusunan studi ini prosedur penelitian dilakukan dalam empat tahap. Tahap awal, melakukan analisa dengan sumber studi literatur buku, jurnal dan penelitian terdahulu tentang kestabilan arah kendaraan. Selanjutnya adalah penentuan objek mobil yang akan diteliti yaitu mobil formula Sapuangin Speed 6 dengan spesifikasi seperti pada Tabel 1.

\section{A. LSD Drexler FSAE}

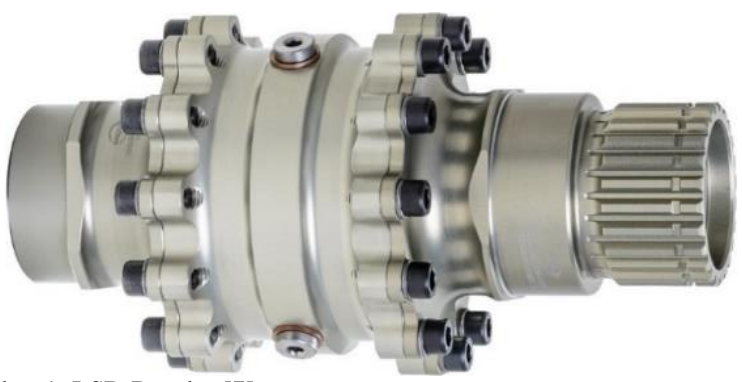

Gambar 1. LSD Drexler [7].

Drexler merupakan suatu perusahaan suplaier part untuk ajang FSAE, dimana salah satu part yang disuplai adalah LSD. Drexler memproduksi suatu LSD khusus yang dapat digunakan tim untuk mengikuti ajang FSAE, dimana spesifikasi yang dimiliki LSD keluaran Drexler ini disesuaikan dengan kebutuhan mobil formula student. Dengan berat sekitar $2 \mathrm{~kg}$, maksimal torsi yang dapat diberikan $1200 \mathrm{Nm}$, initial torque nya $20-25 \mathrm{Nm}$.

Dari gambar 1 tampak bahwa LSD ini memang didesain khusus untuk FSAE, yang dimana hanya memiliki ukuran kecil dan berat yang lumayan ringan dibandingkan dengan LSD Cusco yang dipakai saat ini. Untuk pengoperasian dan maintenance nya dibuat lebih mudah, agar ketika dalam perlombaan LSD ini membutuhkan perlakuan maka akan mudah diselesaikan, semisal untuk menambah oli LSD cukup dengan menambah oli melalui saluran yang ditutup baut yang berada ditengah LSD tersebut.

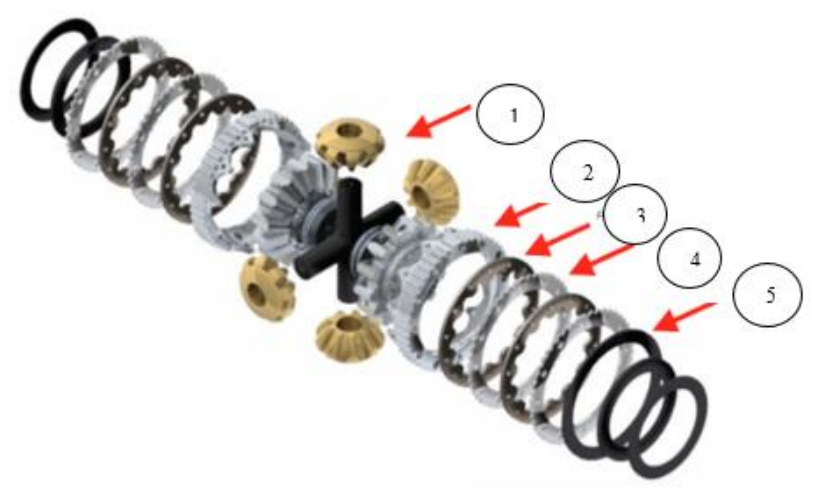

Gambar 2. Bagian-bagian LSD Drexler [7]

Keterangan:
1. Spider gear and side bevel gear
2. Pressure ring
3. Friction disc
4. Clutch plate
5. Disc spring

Mulai dari tengah yang ditunjukkan oleh panah warna merah, adalah spider gear dan side bevel gear yang berfur sebagai open differential. Jadi komponen utama dari oper differential adalah bagian tengah ini dimana fungsinya menjadi gardan biasa yang dapat membedakan putaran roda 
kanan dan kiri ketika mobil berbelok. Ditengah-tengah LSD ada pin (spider axle) yang berfungsi sebagai penyambung spider gear yang berada didua sisi berbeda. Dan pin ini juga yang pada LSD ini berfungsi sebagai alat untuk mengaktivasi LSD dengan cara menekan pressure ring yang diakibatkan putaran housing. Kemudian disisi luar bevel gear terdapat pressure ring yang ditunjuk panah warna merah, pressure ring ini merupakan bagian LSD yang terdapat ramp angle, tempat pin menekan LSD. Selanjutnya ada kombinasi antara friction disc dan clutch disc, yang befungsi sebagai kopling. Ada beberapa variasi untuk pemasangan plat ini, seperti friction disc|clutch plate|friction disc|clutch plate (0101) $100 \%$ lock atau friction disc|friction disc|clutch plate|clutch plate (0011) 60\% lock, hal ini dilakukan untuk mendapatkan variasi locking yang bisa didapatkan dari LSD ini. Dan yang terakhir adalah disc (cone) spring, bagian ini berfungsi untuk memberikan tekanan terhadap kopling LSD, dan dari spring inilah yang mempengaruhi initial torque suatu LSD berdasarkan kekakuan spring yang dimiliki.

\section{B. Cara Kerja LSD Drexler}

Pada gambar 3 menunjukkan bagaimana pin (spider axle) begerak, panah warna kuning menunjukkan arah putaran final drive pada mobil. Ketika panah warna kuning bergerak kebawah dengan torsi sebesar $\mathrm{X}$, maka spider axle akan bergerak searah panah berwarna biru dengan torsi sebesar $\mathrm{X}$ pula. Akibat adanya ramp angle, menyebabkan gaya dorong oleh pin dapat diteruskan ke arah plat kopling sesuai arah panah warna merah dengan besar:

$F_{A}=F \cos \theta$

Dimana: $\Theta=$ besar sudut ramp angle

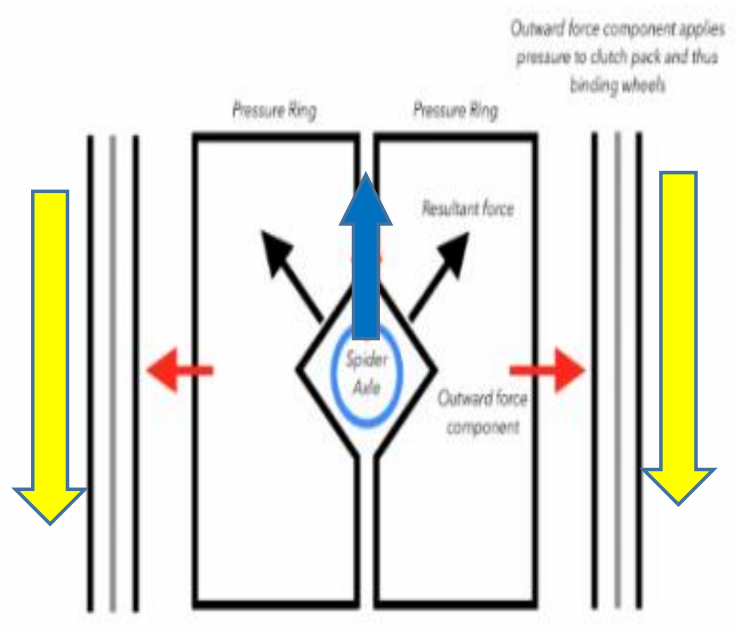

(a)

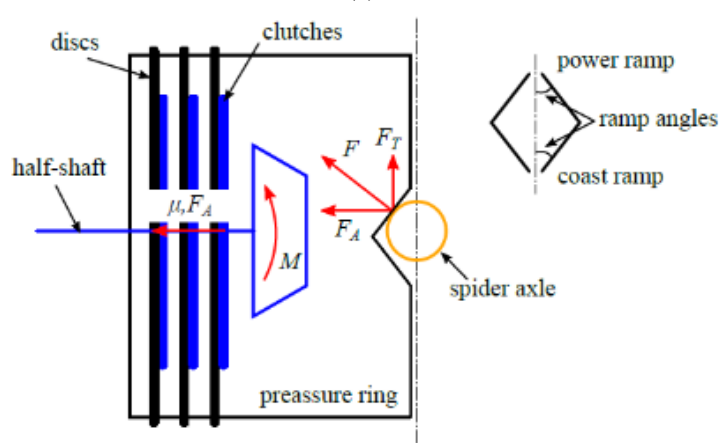

(b)

Gambar 3. (a) (b) Kerja spider axle ketika LSD berputar [7]

Ketika housing LSD berputar diakibatkan putaran dari final drrive, housing juga akan memutar pressure ring dan clutch plate. Akibat dari adanya gerak relatif pressure ring ini, maka pin yang berada diantara ramp angle dari pessure ring akan bergerak berlawanan dengan arah final drive. Dan gerakan inilah yang akan menekan pressure ring ke arah plat kopling, ketika kopling bagian kanan dan kiri tertekan oleh pressure ring, maka akan menyebabkan penyaluran torsi yang sama ke kedua roda mobil. Pada LSD Drexler terdapat beberapa ramp angel yang dapat diubah ubah sesuai dengan kebutuhan mobil seperti yang sudah tertera pada gambar diatas, yaitu: $30^{\circ}, 40^{\circ}, 45^{\circ}, 50^{\circ}, 60^{\circ}$, dan $90^{\circ}$ (open differential).

C. Perhitungan Torsi, Traksi dan Vmax tiap tingkat Transmisi SAS 6

Tabel 2. Torsi, Traksi dan V Roda tiap Tingkat Transmisi

\begin{tabular}{ccccccccc}
\hline $\begin{array}{c}\text { Torsi } \\
\text { Engine } \\
(\mathrm{Nm})\end{array}$ & $\begin{array}{c}\text { RPM } \\
\text { engine }\end{array}$ & it & Ig & $\begin{array}{c}\text { r roda } \\
(\mathrm{m})\end{array}$ & $\begin{array}{c}\text { Torsi roda } \\
(\mathrm{Nm})\end{array}$ & $\begin{array}{c}\text { RPM } \\
\text { roda }\end{array}$ & $\begin{array}{c}\text { Ft roda } \\
(\mathrm{N})\end{array}$ & $\begin{array}{c}\text { Vmax } \\
(\mathrm{m} / \mathrm{s})\end{array}$ \\
\hline 32,5 & 8300 & 2,714 & 3,25 & 0,127 & 286,67 & 940,99 & 2144,35 & 12,52 \\
32,5 & 8300 & 2,2 & 3,25 & 0,127 & 232,38 & 1160,84 & 1738,24 & 15,44 \\
32,5 & 8300 & 1,85 & 3,25 & 0,127 & 195,41 & 1380,46 & 1461,70 & 18,37 \\
32,5 & 8300 & 1,6 & 3,25 & 0,127 & 169,00 & 1596,15 & 1264,17 & 21,24 \\
32,5 & 8300 & 1,421 & 3,25 & 0,127 & 150,09 & 1797,22 & 1122,74 & 23,91 \\
32,5 & 8300 & 1,3 & 3,25 & 0,127 & 137,31 & 1964,50 & 1027,14 & 26,14 \\
\hline
\end{tabular}

Untuk menentukan Ft (Gaya Traksi) menggunakan persamaan:

$F t=\frac{\text { it } x \text { ig } x \text { T engine }}{r \text { roda }} \eta t$

$\eta \mathrm{t}=0,95$

Dan untuk menentukan Vmax tiap transmisi pada saat torsi maksimum menggunakan persamaan:

$V k=\frac{n e \times 2 \pi r}{i k \times i g \times 60}$

Peak torsi yang dihasilkan mesin jika disalurkan pada roda akan bernilai seperti pada tabel 2. Pada pebandingan kecepatan 1 dengan perbandingan transmisi yang besar $(2,714)$ menyebabkan rpm yang disalurkan pada poros bernilai kecil, maka torsi poros/roda akan besar dan kecepatan maksimal yang dapat dicapai kecil. Semakin kecil perbandingan transmisi, maka torsi yang disalurkan menuju poros juga akan semakin kecil dan kecepatan yang dapat dicapai semakin besar. Seperti pada transmisi 1, dengan perbandingan 2,714 dapat menghasilkan torsi $286,67 \mathrm{Nm}$, namun kecepatan maksimal yang dapat dicapai hanya sebesar $12,52 \mathrm{~m} / \mathrm{s}$. Berlawanan dengan transmisi 6 yang hanya dapat menghasilkan torsi $137,31 \mathrm{Nm}$, namun kecepatan maksimal yang dapat ditempuh adalah $26,14 \mathrm{~m} / \mathrm{s}$. Data pada tabel $1 \mathrm{ini}$ menunjukkan kemampuan seberapa besar mobil SAS 6 dapat dipacu dan menjadi acuan dalam mendesain mobil SAS 6.

\section{Analisa Skid Kendaraan}

Mobil akan skid apabila gaya sentrifugal yang tejadi pada kendaraan berbelok lebih besar dari pada gaya gesek antara ban dan permukaan. Maka dari itu dibutuhkan Vsmax agar roda tidak skid. Untuk analisa skid menggunakan persamaan:

$V_{f s}=\sqrt{\frac{R_{n} \cdot g}{W}\left[\frac{\mu \cdot b\left(W-F_{L}\right)-b \cdot F_{S}-F_{d} \cdot h \cdot \mu-\mu \cdot M_{p a}}{b \cdot \cos \beta-h \cdot \mu \cdot \sin \beta}\right]}$
$V_{r s}=\sqrt{\frac{R_{n} \cdot g}{W}\left[\frac{\mu \cdot a\left(W-F_{L}\right)-a \cdot F_{S}-F_{d} \cdot h \cdot \mu-\mu \cdot M_{p a}}{a \cdot \cos \beta-h \cdot \mu \cdot \sin \beta}\right]}$

Dari persamaan (4) dan (5) didapatkan Tabel 3 sampai Tabel 5 hasil dari perhitungan skid: 
Tabel 3. Vfs, Vrs dan Vsmax pada Lintasan Skidpad dengan Radius 8,55 meter

\begin{tabular}{|c|c|c|c|c|}
\hline $\begin{array}{c}\text { Vtarget } \\
(\mathrm{m} / \mathrm{s})\end{array}$ & Vfs $(\mathrm{m} / \mathrm{s})$ & $\operatorname{Vrs}(\mathrm{m} / \mathrm{s})$ & $\operatorname{Vsmax}(\mathrm{m} / \mathrm{s})$ & $\begin{array}{c}\text { Vtarget }< \\
\text { Vsmax }\end{array}$ \\
\hline 11,05820106 & 13,40036 & 12,92346 & 13,10903028 & \multirow{6}{*}{ 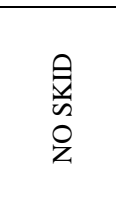 } \\
\hline 10,95674967 & 13,4011 & 12,92286 & 13,10903028 & \\
\hline 10,90782568 & 13,40145 & 12,92257 & 13,10903028 & \\
\hline 10,83306937 & 13,40199 & 12,92214 & 13,10903028 & \\
\hline 10,75502444 & 13,40254 & 12,92168 & 13,10903028 & \\
\hline 7,685236257 & 13,42119 & 12,90648 & 13,10903028 & \\
\hline
\end{tabular}

Tabel 4. Vfs, Vrs dan Vsmax pada Lintasan Autocross dengan Radius 4,5 meter

\begin{tabular}{ccccc}
\hline Vtarget $(\mathrm{m} / \mathrm{s})$ & Vfs $(\mathrm{m} / \mathrm{s})$ & Vrs $(\mathrm{m} / \mathrm{s})$ & Vsmax $(\mathrm{m} / \mathrm{s})$ & $\begin{array}{c}\text { Vtarget> } \\
\text { Vsmax }\end{array}$ \\
\hline 14,52911237 & 9,251804 & 8,958579 & 9,111642552 & \\
14,19803168 & 9,253979 & 8,956816 & 9,111642552 & \\
14,19227447 & 9,254016 & 8,956786 & 9,111642552 & 离 \\
14,14514145 & 9,254321 & 8,956538 & 9,111642552 & \\
14,10548449 & 9,254577 & 8,95633 & 9,111642552 & \\
10,10139035 & 9,276704 & 8,938344 & 9,111642552 & \\
\hline
\end{tabular}

Tabel 5. Vfs, Vrs dan Vsmax pada Lintasan Endurance dengan Radius 4,5 meter

\begin{tabular}{ccccc}
\hline Vtarget $(\mathrm{m} / \mathrm{s})$ & Vfs $(\mathrm{m} / \mathrm{s})$ & Vrs $(\mathrm{m} / \mathrm{s})$ & Vsmax $(\mathrm{m} / \mathrm{s})$ & $\begin{array}{c}\text { Vtarget }> \\
\text { Vsmax }\end{array}$ \\
\hline 15,62725308 & 9,24423 & 8,964714 & 9,111642552 & \\
15,59792519 & 9,24444 & 8,964545 & 9,111642552 & \\
15,56727504 & 9,244658 & 8,964368 & 9,111642552 & $\ominus$ \\
15,48026829 & 9,245276 & 8,963867 & 9,111642552 & $\sqrt{\sim}$ \\
15,34448366 & 9,246234 & 8,963092 & 9,111642552 & \\
11,9853996 & 9,267211 & 8,94607 & 9,111642552 & \\
\hline
\end{tabular}

Pada Tabel 3 sampai Tabel 5 menunjukkan hasil perhitungan untuk analisa skid mobil SAS 6 pada 3 jenis lintasan SFJ. Dari tabel-tabel tersebut dapat dilihat bahwa pada belokan yang memiliki radius terkecil (autocross dan endurance) yaitu 4,5 meter mobil SAS 6 akan mengalami skid. Pada lintasan skidpad yang radiusnya 8,55 meter mobil tidak skid. Nilai Vsmax, yaitu nilai kecepatan ijin agar mobil tidak mengalami skid pada lintasan belok dengan radius 4,5 meter adalah $9,111642552 \mathrm{~m} / \mathrm{s}$, sedangkan kecepatan targetnya melebihi kecepatan ijin.

\section{E. Analisa Guling Kendaraan}

Kendaraan dalam keadaan kritis mulai akan terguling jika ada salah satu atau dua roda yang terangkat ketika berbelok. Kondisi ini sangat penting untuk diketahui oleh driver agar bisa mengendalikan mobil dengan baik. Untuk analisa skid menggunakan persamaan:

$$
\begin{aligned}
& V_{f g}=\sqrt{R \cdot g \frac{\left(b \cdot t_{f}\left(W-F_{L}\right)-t_{f}\left(F_{d} \cdot h+M_{R a}\right)+2 b\left(F_{s} \cdot h+M_{R a}\right)\right.}{W(2 \cdot b \cdot h \cos \beta+h \cdot t f \cdot \sin \beta)}} \\
& V_{r g}=\sqrt{R \cdot g \frac{\left(a \cdot t_{r}\left(W-F_{L}\right)+t_{r}\left(F_{d} \cdot h+M_{p a}\right)+2 a\left(F_{s} \cdot h+M_{p a}\right)\right.}{W(2 \cdot a \cdot h \cos \beta+h \cdot t r \cdot \sin \beta)}}
\end{aligned}
$$

Dari persamaan (6) dan (7) didapatkan Tabel 6 sampai Tabel 8 berikut:

Tabel 6. Vfg, Vrg dan Vgmax pada Lintasan Skidpad dengan Radius 8,55 meter

\begin{tabular}{ccccc}
\hline Vtarget $(\mathrm{m} / \mathrm{s})$ & $\operatorname{Vfg}(\mathrm{m} / \mathrm{s})$ & $\operatorname{Vrg}(\mathrm{m} / \mathrm{s})$ & $\operatorname{Vgmax}(\mathrm{m} / \mathrm{s})$ & $\begin{array}{c}\text { Vtarget } \\
\text { Vgmax }\end{array}$ \\
\hline 11,05820106 & 13,05226 & 12,74054 & 12,7759622 & \\
10,95674967 & 13,05297 & 12,74119 & 12,7759622 & \\
10,90782568 & 13,05332 & 12,7415 & 12,7759622 & $\bigcirc$ \\
10,83306937 & 13,05384 & 12,74197 & 12,7759622 & $\wp$ \\
10,75502444 & 13,05438 & 12,74246 & 12,7759622 & $\bigcirc$ \\
7,685236257 & 13,07254 & 12,75886 & 12,7759622 & \\
\hline
\end{tabular}

Tabel 7. Vfg, Vrg dan Vgmax pada Lintasan Autocross dengan Radius 4,5

\begin{tabular}{|c|c|c|c|c|}
\hline Vtarget $(\mathrm{m} / \mathrm{s})$ & Vfg $(\mathrm{m} / \mathrm{s})$ & $\operatorname{Vrg}(\mathrm{m} / \mathrm{s})$ & $\operatorname{Vgmax}(\mathrm{m} / \mathrm{s})$ & $\begin{array}{l}\text { Vtarget> } \\
\text { Vgmax }\end{array}$ \\
\hline 14,52911237 & 9,103899 & 8,887931 & 8,93072075 & \multirow{6}{*}{$\stackrel{\oslash}{ٍ}$} \\
\hline 14,19803168 & 9,106039 & 8,889864 & 8,93072075 & \\
\hline 14,19227447 & 9,106076 & 8,889897 & 8,93072075 & \\
\hline 14,14514145 & 9,106376 & 8,890168 & 8,93072075 & \\
\hline 14,10548449 & 9,106628 & 8,890396 & 8,93072075 & \\
\hline 10,10139035 & 9,128401 & 8,910063 & 8,93072075 & \\
\hline
\end{tabular}
meter

Tabel 8. Vfg, Vrg dan Vgmax pada Lintasan Endurance dengan Radius 4,5 meter

\begin{tabular}{ccccc}
\hline Vtarget $(\mathrm{m} / \mathrm{s})$ & $\operatorname{Vfg}(\mathrm{m} / \mathrm{s})$ & $\operatorname{Vrg}(\mathrm{m} / \mathrm{s})$ & $\operatorname{Vgmax}(\mathrm{m} / \mathrm{s})$ & $\begin{array}{c}\text { Vtarget }> \\
\text { Vgmax }\end{array}$ \\
\hline 15,62725308 & 9,096446 & 8,8812 & 8,93072075 & \\
15,59792519 & 9,096653 & 8,881386 & 8,93072075 & \\
15,56727504 & 9,096868 & 8,88158 & 8,93072075 & $\Xi$ \\
15,48026829 & 9,097476 & 8,88213 & 8,93072075 & $\precsim$ \\
15,34448366 & 9,098418 & 8,882981 & 8,93072075 & \\
11,9853996 & 9,11906 & 8,901625 & 8,93072075 & \\
\hline
\end{tabular}

Pada Tabel 6 sampai Tabel 8 menunjukkan hasil perhitungan untuk analisa guling mobil SAS 6 pada 3 jenis lintasan SFJ. Dari tabel-tabel tersebut dapat dilihat bahwa pada belokan yang memiliki radius terkecil (autocross dan endurance) yaitu 4,5 meter mobil SAS 6 akan mengalami guling. Pada lintasan skidpad yang radiusnya 8,55 meter mobil tidak guling. Nilai Vgmax, yaitu nilai kecepatan ijin agar mobil tidak mengalami guling pada lintasan belok dengan radius 4,5 meter adalah $8,93072075 \mathrm{~m} / \mathrm{s}$, sedangkan kecepatan targetnya melebihi kecepatan ijin.

\section{F. Gaya Hambat Kendaraan}

Pada gambar 4. menunjukkan total hambatan yang harus dilawan oleh mobil pada saat melaju pada kecepatan tertentu. Dengan menjumlahkan hambatan udara ( $\mathrm{Ra}$ ) dan hambatan rolling $(\mathrm{Rr})$ didapatkan hambatan total $(\mathrm{Fr})$. Ra didapat dari input data variabel bebas kendaraan yaitu luas penampang frontal kendaraan (Af), $\mathrm{C}_{\mathrm{D}}$ dan $\mathrm{C}_{\mathrm{L}}$ yang didapat dari hasil simulasi yaitu berturut-turut sebesar $1,002 \mathrm{~m}^{2} ; 0,605$; 0,00868. Dan menggunakan variabel tetap massa jenis udara ( $\rho$ ) sebesar $1,2 \mathrm{~kg} / \mathrm{m}^{3}$, melalui persamaan gaya hambat udara akan didapatkan gaya hambat dengan fungsi kecepatan. Gaya hambat rolling didapatkan dari perkalian berat kendaraan dengan koefisien rolling (fr), dimana koefisien rolling dari roda yang digunakan mobil SAS 6 telah ditentukan oleh produsen roda tersebut sebesar 0,013 untuk ban depan (Hoosier LC0 6.0x18.0-10) dan 0,010 untuk ban belakang (Hoosier R25B 18.0x6.0-10).

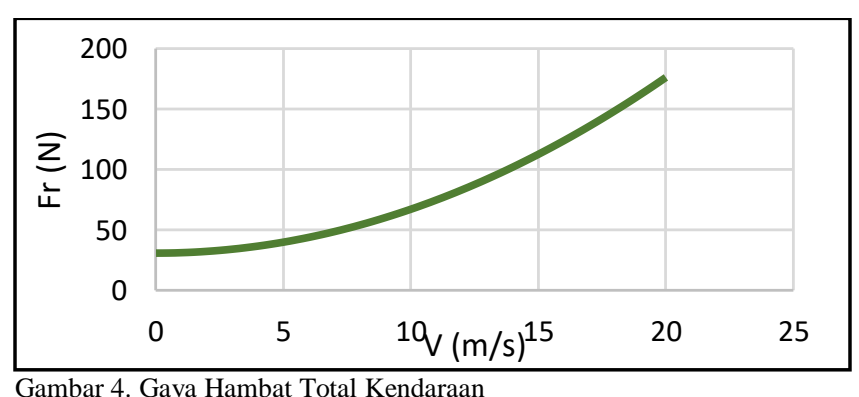

Gambar 4. Gaya Hambat Total Kendaraan

\section{G. Perhitungan Tenaga dan Torsi untuk Melawan Gaya Hambat}

Gaya hambat total kendaraan (Fr) sama dengan gaya dorong kendaraan yang harus dikeluarkan mesin untuk melawan gaya hambat total (Fr), dari gaya dorong yang 
dihasilkan oleh kendaraan dapat diketahui Road-Load Horse Power (Rhp) kendaraan dengan menggunakan rumus:

$R h p=F x V$

$R h p=(R a+R r) x V$

$R h p=\left(f r . W+1 / 2 \cdot C_{D} \cdot A_{f} \cdot V^{2}\right) x V$

Gambar 5. menunjukkan grafik Rhp kendaraan yang diperlukan untuk melawan gaya hambat total.

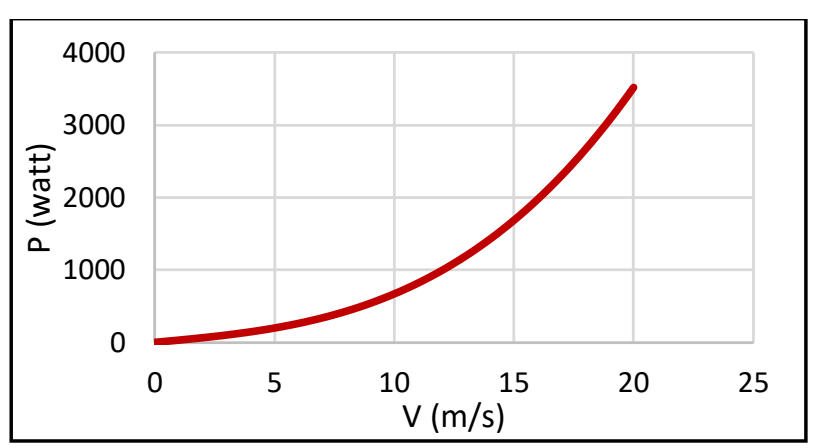

Gambar 5. Rhp terhadap Kecepatan Kendaraan.

Selain bisa mendapatkan Rhp mobil, dari gaya dorong kendaraan juga bisa didapatkan Torsi roda mobil yang digunakan untuk melawan gaya hambat total kendaraan. Pada gambar 6. merupakan hasil perhitungan torsi roda untuk melawan gaya hambat kendaraan, perhitungan ini didapatkan dari rumus:

$T$ roda $=$ Fr $x$ R roda

$T$ roda $=(R a+R r) \times R$ roda

$T$ roda $=\left(\right.$ fr. $\left.W+1 / 2 \cdot \rho \cdot C_{D} \cdot A_{f} \cdot V^{2}\right) \times 0,127$

Gambar 6. menunjukkan hasil perhitungan torsi roda untuk melawan gaya hambat yang bekerja pada mobil pada setiap tingkat kecepatan kendaraan.

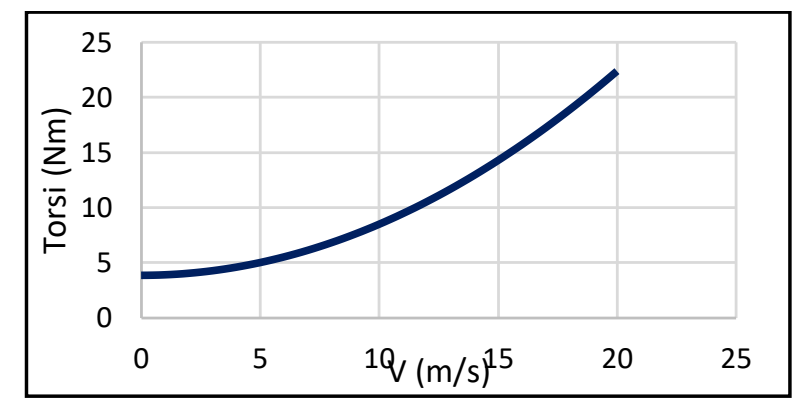

Gambar 6. Torsi roda terhadap Kecepatan Kendaraan

\section{HASIL DISKUSI}

Untuk menganalisa pengaruh penggunaan LSD pada mobil SAS 6, dilakukan perhitungan pada belokan kritis dilintasan SFJ. Dari hasil perhitungan skid dan guling belokan kritis terjadi di hairpin turns pada autocross dan endurance. Berdasarkan FSAE rules 2017-2018 hairpin turns memiliki radius minimum 4,5 meter. Pada analisa $L S D$ ini akan dilakukan pada belokan hairpin turns pada radius 4,5 meter, 5 meter, 5,5 meter, 6 meter, 6,5 meter, 7 meter, 7,5 meter, 8 meter dan 8,5 meter, dimana hairpin turns merupakan lintasan berbentuk setengah lingkaran.

\section{H. Analisa LSD}

Untuk menentukan kapan LSD dibutuhkan pada hairpin turns, maka perlu dilakukan analisa perhitungan pada beberapa radius untuk menentukan kapan roda bagian belakang terjadi skid ketika roda terangkat dan analisa ini menggunakan kecepatan maksimal mobil pada saat power peak engine yaitu $18,37 \mathrm{~m} / \mathrm{s}$, hal ini disebabkan untuk mendapatkan juara 1 pada endurance kecepatan harus lebih tinggi dari juara 1 endurance $(15,627 \mathrm{~m} / \mathrm{s})$.

Pada radius 4,5 meter $(\mathrm{V}=18,37 \mathrm{~m} / \mathrm{s})$ :

$F c r=\frac{a}{a+b} x \frac{W x V^{2}}{g x R}$

$W r=\frac{a}{a+b} x W$

$a=\frac{F c r-F g r}{W r / g}$

$\tan \theta=\frac{\left(W r \cdot \frac{t r}{2}-F c r . h\right)}{\left(F c r \cdot \frac{t r}{2}+W r \cdot h\right)}$

Jika nilai $a$ positif, maka mobil akan mengalami skid pada saat roda mengangkat, dan mobil membutuhkan LSD. Dan $\Theta$ adalah besar sudut angkat suatu mobil pada saat mobil tersebut berbelok dan terjadi rolling. Dari hasil perhitungan berdasarkan hasil SFJ 2018, didapatkan tabel 9.

Dari tabel 9. dapat diketahui dengan kecepatan $18,37 \mathrm{~m} / \mathrm{s}$ mobil akan mengalami skid ketika roda dalam terangkat pada semua radius. Maka mobil membutuhkan LSD agar dapat tetap melaju kedepan pada semua radius. Karena ketika tidak menggunakan LSD, roda belakang mobil tidak memiliki power dan torsi untuk melaju ke depan. Sehingga roda mobil kehilangan traksinya dan gaya terbesar yang bekerja adalah gaya kesamping (sentrifugal) pada roda belakang.

Tabel 9. Perhitungan Percepatan Roda Belakang

\begin{tabular}{ccccccccc}
\hline $\begin{array}{c}\text { R belok } \\
(\mathrm{m})\end{array}$ & $\begin{array}{c}\mathrm{V} \\
\text { mobil } \\
(\mathrm{m} / \mathrm{s})\end{array}$ & $\begin{array}{c}\mathrm{Fc} \\
\text { belakang } \\
\text { mobil }(\mathrm{N})\end{array}$ & $\begin{array}{c}\mathrm{W} \\
\text { belakang } \\
\text { mobil }(\mathrm{N})\end{array}$ & $\begin{array}{c}\text { F gesek } \\
\text { roda } \\
\text { belakang } \\
\text { mobil }(\mathrm{N})\end{array}$ & $\begin{array}{c}\text { a roda } \\
\text { searah Fc } \\
\left(\mathrm{m} / \mathrm{s}^{2}\right)\end{array}$ & $\begin{array}{c}\text { Sudut } \\
\text { angkat } \\
\text { roda } \\
\left(\Theta^{\circ}\right)\end{array}$ & Ket \\
\hline 4,5 & 11694,25 & & & 0,694 & $-0,325$ & 17,999 & LSD \\
5 & & 10524,82 & & & 0,597 & $-0,309$ & 17,181 & LSD \\
5,5 & & 9568,021 & & & 0,517 & $-0,294$ & 16,367 & LSD \\
6 & & 8770,686 & & & 0,451 & $-0,278$ & 15,557 & LSD \\
6,5 & 18,37 & 8096,018 & 1530,36 & 3336,185 & 0,395 & $-0,263$ & 14,750 & LSD \\
7 & & 7517,731 & & & 0,347 & $-0,248$ & 13,948 & LSD \\
7,5 & 7016,549 & & & 0,305 & $-0,234$ & 13,151 & LSD \\
8 & 6578,015 & & & 0,269 & $-0,219$ & 12,358 & LSD \\
8,5 & 6191,073 & & & 0,237 & $-0,205$ & 11,570 & LSD \\
\hline
\end{tabular}

Selanjutnya adalah menghitung seberapa besar pengaruh penggunaan LSD pada power output, torsi output dan kecepatan yang dapat dicapai oleh mobil pada saat berbelok pada hairpin turns. Power output mesin yang digunakan adalah saat peak torque transimisi 3, yaitu sebesar 27819,67 watt. Maka hasil distribusi power yang melalui LSD dengan peak power saat transmisi 3 seperti pada tabel 10 .

$P_{t r}=P_{1}+P_{2}$

$T_{t r} \omega_{t r}=T_{1} \omega_{1}+T_{2} \omega_{2}$

$P_{r}=\left(R_{r}+R_{a}\right) x V$

$P_{r}=\left(W \cdot f r+1 / 2 \cdot \rho \cdot C_{D} \cdot A_{f} \cdot V^{2}\right) x V$

Gambar 7. merupakan pengaruh locking percentage LSD terhadap tenaga keluaran mesin yang bekerja pada roda untuk melawan hambatan total mobil. Dari gambar 4.5 dapat diketahui semakin besar nilai locking percentage LSD maka semakin besar tenaga yang dapat disalurkan pada roda yang memiliki hambatan (roda luar). Nilai power keluar yang dapat disalurkan menuju roda luar paling kecil adalah ketika 
Tabel 10. Perhitungan Pengaruh LSD

\begin{tabular}{cccccc}
\hline $\begin{array}{c}\text { Locking } \\
\text { percentage } \\
\text { clutch (\%) }\end{array}$ & $\begin{array}{c}\text { Locking } \\
\text { percentage } \\
\text { ramp }(\%)\end{array}$ & $\begin{array}{c}\text { Locking } \\
\text { percentage } \\
\text { total LSD } \\
(\%)\end{array}$ & $\begin{array}{c}\text { Power } \\
\text { roda luar } \\
\text { (watt) }\end{array}$ & $\begin{array}{c}\text { Kecepatan } \\
\text { roda luar } \\
(\mathrm{m} / \mathrm{s})\end{array}$ & $\begin{array}{c}\text { Torsi } \\
\text { roda } \\
\text { luar } \\
(\mathrm{Nm})\end{array}$ \\
\hline & 0 & 0 & 0 & 0 & 3,884 \\
0,6 & 0,29 & 0,174 & 4840,622 & 22,51633 & 27,303 \\
& 0,42 & 0,252 & 7010,556 & 25,76714 & 34,553 \\
& 0,51 & 0,306 & 8512,818 & 27,6251 & 39,136 \\
& 0,6 & 0,36 & 10015,08 & 29,26899 & 43,456 \\
& 0,88 & 0,528 & 14688,78 & 33,492 & 55,699 \\
& 0 & 0 & 0 & 0 & 3,884 \\
1 & 0,29 & 0,29 & 8067,703 & 27,100 & 37,808 \\
& 0,42 & 0,42 & 11684,26 & 30,907 & 48,010 \\
& 0,51 & 0,51 & 14188,03 & 33,088 & 54,457 \\
& 0,6 & 0,6 & 16691,8 & 35,020 & 60,534 \\
& 0,88 & 0,88 & 24481,31 & 39,989 & 77,750 \\
\hline
\end{tabular}

locking percentage $0 \%$, yaitu 0 watt yang dapat menghasilkan kecepatan roda luar $0 \mathrm{~m} / \mathrm{s}$. Dan nilai power roda luar terbesar yang didapat adalah ketika locking pecentage $0,88 \%$, yaitu 24481,31 watt yang dapat menghasilkan kecepatan roda luar $39,989 \mathrm{~m} / \mathrm{s}$. Semakin besar locking percentage, maka semakin kecil penurunan kecepatan roda luar.

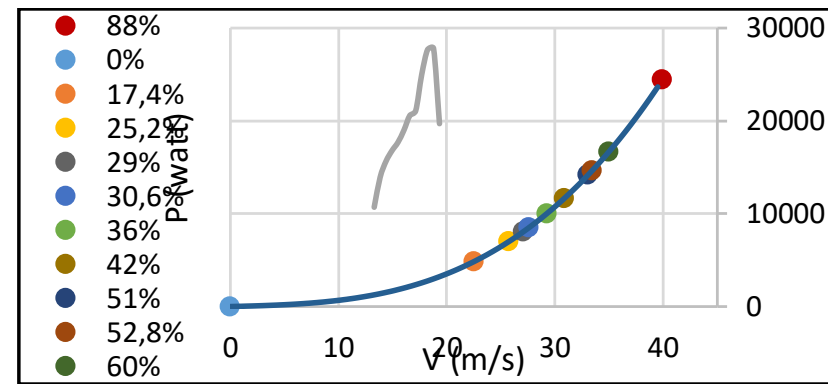

Gambar 7. Grafik Pengaruh LSD pada Power.

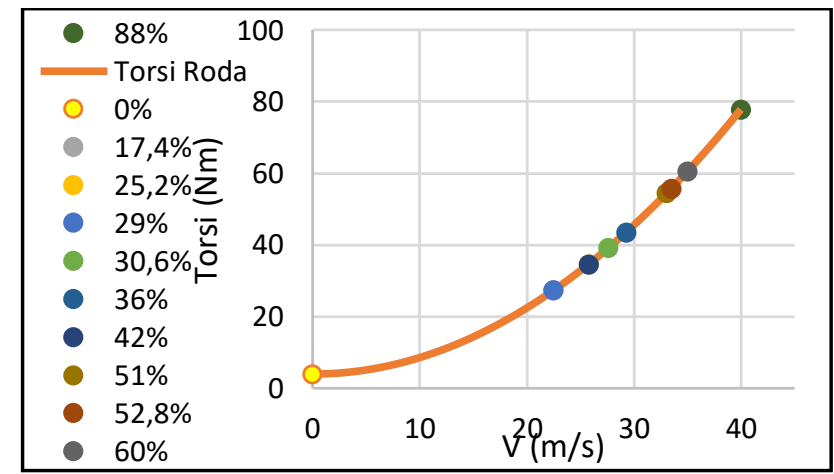

Gambar 8. Grafik Pengaruh LSD pada Torsi.
Pada Gambar 8. adalah pengaruh locking percentage LSD terhadap torsi roda yang bekerja untuk melawan hambatan total mobil. Nilai torsi mesin terkecil yang didapat roda luar adalah ketika locking pecentage $0 \%$, yaitu 3,884 Nm pada saat kecepatan mobil $0 \mathrm{~m} / \mathrm{s}$. Dan nilai torsi roda luar terbesar adalah ketika locking pecentage $0,88 \%$, yaitu 77,750 Nm pada saat kecepatan mobil 39,989 m/s. Dari gambar 4.9 dapat diketahui juga bagaimana untuk memilih jenis LSD yang akan digunakan. Pemilihan LSD didasarkan pada 2 hal, yaitu intial torque dan locking percentage yang dapat dihasilkan. LSD harus aktif ketika salah satu roda mobil dalam keadaan terangkat, maka initial torque LSD adalah $27 \mathrm{Nm}$, agar ketika menggunakan locking percentage $(17,4 \%)$ paling kecil dengan power keluaran engine miniman pada peak power transmisi 3 LSD dapat aktif.

\section{KESIMPULAN}

Limited Slip Differential (LSD) dapat membantu mobil SAS 6 tetap memiliki tenaga dan torsi untuk melawan gaya hambat mobil ketika salah satu roda terangkat, semakin besar locking percentage $L S D$ yang digunakan, maka semakin besar pula tenaga dan torsi yang dapat disalurkan.Terdapat 2 hal yang menjadi acuan pemilihan LSD yang sesuai untuk digunakan pada mobil SAS 6, yaitu initial torque dan locking percentage LSD. Maka initial torque LSD adalah $27 \mathrm{Nm}$ agar ketika menggunakan locking percentage paling kecil $(17,4 \%)$ dengan power keluaran minimal pada peak power saat transmisi 3 LSD dapat aktif.

\section{DAFTAR PUSTAKA}

[1] I. N. Sutantra dan B. Sampurno, "Teknologi Otomotif : Edisi Kedua". Guna Widya., Surabaya (2010)

[2] J. Allen, “ 4-Wheeler's Bible”. MBI Publishing Company, 380 Jackson Street, Suite 200, St.Paul., USA (2002)

[3] T. R. Pradana, "Analisa Perilaku Arah Kendaraan dengan Variasi Posisi Titik Berat, Sudut Belok dan Kecepatan Pada Mobil Formula Sapuangin Speed 3"'. Teknik Mesin ITS., Surabaya (2016)

[4] Formula SAE rules by SAE International. (2018, Oktober 07). [Online]. Available: https://www.jsae.or.jp/formula/en/

[5] J. Rendl, L. Zilli, dan F. Sedláček. "Investigation of driving properties for Formula Student”. Applied Mechanics 2018 Publishing. Myslovice, Czech Republic (2018)

[6] Cusco Japan., Ltd. (2018, Oktober 07). [Online]. Available: https://www.cusco.co.jp/en/

[7] Motosport, Drexler. (2018, Oktober 07). [Online]. Available:https://eng.drexlerautomotive.com/motorsport/formulastudent 